\title{
A heat pipe heat recovery heat exchanger for a mini-drier
}

\author{
A Meyer \\ Department of Mechanical Engineering, University of Stellenbosch, Stellenbosch
}

R T Dobson

Department of Mechanical Engineering, University of Stellenbosch, Stellenbosch

\begin{abstract}
This paper considers the thermal design and the experimental testing of a heat pipe (thermosyphon) heat exchanger for a relatively small commercially available mini-drier. The purpose of the heat exchanger is to recover heat from the moist waste air stream to preheat the fresh incoming air. The working fluid used was R134a and the correlations are given for the evaporator and condenser inside heat transfer coefficients as well as for the maximum heat transfer rate. The theoretical model and computer simulation program used for the thermal design calculations are described. The validity of the as-designed and manufactured heat exchanger coupled to the drier is experimentally verified. The theoretical model accurately predicted the thermal performance and a significant energy savings and a reasonable payback period was achieved.
\end{abstract}

Keywords: Heat pipe heat exchangers, thermosyphons, air drying, energy savings

\section{Nomenclature}

A Area, $m^{2}$

Bo Bond number, $d / \sqrt{\sigma / \mathrm{g}\left(\rho_{1}-\rho_{\mathrm{v}}\right)}$

$\mathrm{c}_{\mathrm{p}}$ specific heat (at constant pressure), $\mathrm{J} / \mathrm{kg}^{\circ} \mathrm{C}$

$\mathrm{d}$ diameter, $\mathrm{m}$

g gravitational constant, $9.81 \mathrm{~m} / \mathrm{s}^{2}$

h heat transfer coefficient, $\mathrm{W} / \mathrm{m}^{2 \circ} \mathrm{C}$

$h_{\mathrm{fg}} \quad$ latent heat of vaporization, $\mathrm{J} / \mathrm{kg}$

$\mathrm{Ja} \quad$ Jacob number, $c_{\mathrm{pl}}\left(T_{\mathrm{w}}-T_{\mathrm{sat}}\right) / h_{\mathrm{fg}}$

$k$ thermal conductivity, $\mathrm{W} / \mathrm{m}^{\circ} \mathrm{C}$

$\mathrm{Ku} \quad$ Kutateladze number,

$L \quad$ length, $m$

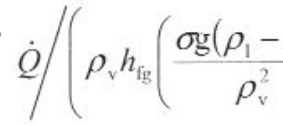

mass flow rate, $\mathrm{kg} / \mathrm{s}$

$P \quad$ pressure, $\mathrm{Pa}$

heat transfer rate, $\mathrm{W}$

$R \quad$ thermal resistance, ${ }^{\circ} \mathrm{C} / \mathrm{W}$

Re Reynolds number, $R e=4 \dot{Q} /\left(\pi d \mu h_{\mathrm{fg}}\right)$

$t$ time, $\mathrm{s}$ or $\mathrm{h}$
T temperature, ${ }^{\circ} \mathrm{C}$

average temperature, ${ }^{\circ} \mathrm{C}$

$\begin{array}{ll}\text { Subscripts and superscripts } \\ \text { c } & \text { condenser, cold } \\ \text { e } & \text { evaporator, exit } \\ \text { h } & \text { hot } \\ \text { hp } & \text { heat pipe } \\ \text { i } & \text { inlet, inside } \\ \text { l } & \text { liquid } \\ \text { max } & \text { maximum } \\ \text { new } & \text { new } \\ \text { o } & \text { outside } \\ \text { v } & \text { vapour } \\ \text { w } & \text { water }\end{array}$

\section{Greek symbols}

$\rho$ density, $\mathrm{kg} / \mathrm{m}^{3}$

$v \quad$ kinematic viscosity, $\mathrm{m}^{2} / \mathrm{s}$

$\phi \quad$ relative humidity

$\mu \quad$ dynamic viscosity, $\mathrm{kg} / \mathrm{ms}$

$\sigma \quad$ surface tension, $\mathrm{N} / \mathrm{m}$ 
large quantities of moist hot air back into the atmosphere.

A HPHE is a liquid coupled indirect heat transfer type heat exchanger and employs a number of individually-sealed or groups of sealed heat pipes or thermosyphons as the major heat transfer means from the high temperature to the low temperature fluid. Each heat pipe is lined with a wicking structure in which a small amount of working fluid is present and can be divided into an evaporator or heat addition section and a condenser or heat rejection section. When heat is added to the evaporator section, the working fluid present in the wicking structure is heated, vaporizes and flows to the cooler section, condenses and, in so doing, giving up its latent heat of vaporization. The capillary forces in the wicking structure then pump the liquid back to the evaporator (Dunn and Reay, 1994).

Thermosyphons on the other hand are essentially heat pipes but without the wicking structure. The difference between the two is that the thermosyphon uses gravity to transfer heat from a heat source that is located below the cold sink. As a result, the evaporator section is situated below the condenser section. The working fluid evaporates, condenses in the condenser section and flows back to the evaporator section under the influence of gravity. It has been shown that in the presence of gravity, thermosyphons are preferred to heat pipes owing to the fact that the wicks in heat pipes produce an additional resistance to the flow of condensate (Pioro and Pioro, 1997). Figure 1 illustrates the principal difference between the heat pipe and the thermosyphon.

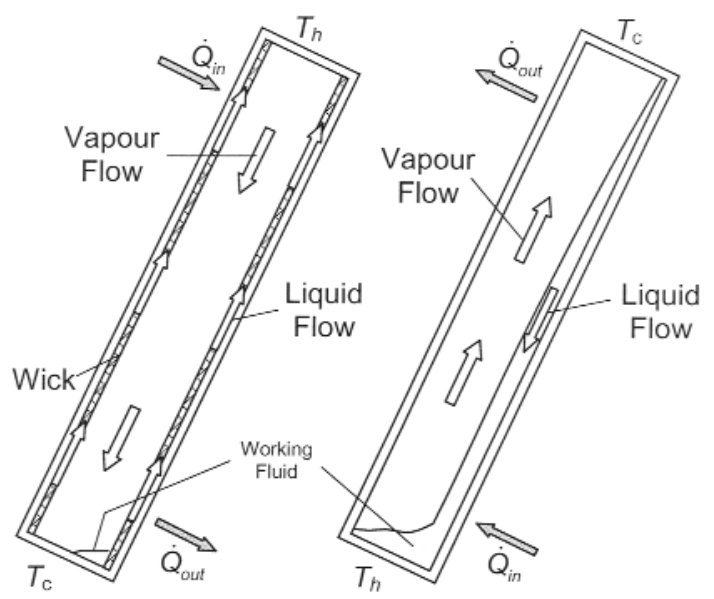

Figure 1: Principal difference between the thermosyphon and heat pipe

The use of heat pipes or thermosyphons in the heat exchanger configuration is ever-increasing in popularity and is attributed to thermosyphons having no moving parts and auxiliary working fluid pumping power requirements are therefore not needed. They can be used for gas-to-gas, gas-to-liq- uid and liquid-to-liquid heat exchange. The hot and cold streams of the HPHE can also be completely isolated preventing cross-contamination of the fluids. Because of the individually sealed pipes, should one pipe fail the heat exchanger will still operate. Also, by eliminating the wick and using a commercial refrigerant as working fluid, existing standard HVAC technology is applicable. HPHEs may thus be viewed as being a commercially attractive option to a company in formulating its product range and product energy efficiency rating.

In this paper, the use of a HPHE utilising thermosyphons (instead of the more complicated wicked heat pipes) are considered to recover the waste heat from a relatively small commercially available air dryer and to use this heat to preheat the incoming cold air. (The drier is typically used for small scale drying of fruits, vegetables, herbs, meat and other products and its wet loading capacity is between 50 and $250 \mathrm{~kg}$.) Heat transfer theory not available in the general literature is given with special emphasis on the inside evaporator and condenser heat transfer coefficients and the maximum heat transfer rate using $\mathrm{R} 134 \mathrm{a}$ and Butane as working fluid. A computer program to predict the thermal performance of a HPHE is described. An economic evaluation of the potential energy savings is undertaken and experimentally validated.

\section{Theory}

\subsection{Thermosyphon heat transfer theory}

For a single two-phase closed thermosyphon, as shown in Figure 1, and for the thermal resistance diagram shown in Figure 2, heat is transferred from a heat source, through the evaporator wall, into the working fluid and then out through the condenser to the heat sink. This heat transfer rate may thus be conveniently expressed in terms of a temperature difference and the sum of a series of thermal resistances as:

$$
\dot{Q}=\frac{\bar{T}_{\mathrm{h}}-\bar{T}_{\mathrm{c}}}{\sum R}=\dot{Q}_{\mathrm{c}}=\frac{\bar{T}_{\mathrm{h}}-\bar{T}_{\mathrm{i}}}{\sum R_{\mathrm{e}}}=\dot{Q}_{\mathrm{c}}=\frac{\bar{T}_{\mathrm{i}}-\bar{T}_{\mathrm{c}}}{\sum R_{\mathrm{c}}}
$$

Where

$$
\begin{aligned}
& \bar{T}_{\mathrm{h}}=\left(T_{\mathrm{hi}}+T_{\mathrm{ho}}\right) / 2 \\
& \text { and } \bar{T}_{\mathrm{c}}=\left(T_{\mathrm{ci}}+T_{\mathrm{co}}\right) / 2, \\
& \sum R=R_{\mathrm{e}}+R_{\mathrm{c}}, \sum R_{\mathrm{e}}=R_{\mathrm{eo}}+R_{\mathrm{ew}}+R_{\mathrm{ei}} \\
& \text { and } \sum R_{\mathrm{c}}=R_{\mathrm{ci}}+R_{\mathrm{cw}}+R_{\mathrm{co}} \\
& R_{\mathrm{eo}}=\frac{1}{h_{\mathrm{eo}} A_{\mathrm{co}}}, R_{\mathrm{ew}}=\frac{\ln \left(d_{\mathrm{o}} / d_{\mathrm{i}}\right)}{2 \pi k L_{\mathrm{e}}} \\
& \text { and } R_{\mathrm{ei}}=\frac{1}{h_{\mathrm{ci}} A_{\mathrm{ei}}}
\end{aligned}
$$




$$
\begin{aligned}
& R_{\mathrm{ci}}=\frac{1}{h_{\mathrm{ci}} A_{\mathrm{ci}}}, R_{\mathrm{cw}}=\frac{\ln \left(d_{\mathrm{o}} / d_{\mathrm{i}}\right)}{2 \pi k L_{\mathrm{c}}} \\
& \text { and } R_{\mathrm{co}}=\frac{1}{h_{\mathrm{co}} A_{\mathrm{co}}} \\
& A_{\mathrm{co}}=\pi d_{\mathrm{o}} L_{\mathrm{e}}, A_{\mathrm{ei}}=\pi d_{\mathrm{i}} L_{\mathrm{e}}, A_{\mathrm{ci}}=\pi d_{\mathrm{i}} L_{\mathrm{c}} \\
& \text { and } A_{\mathrm{co}}=\pi d_{\mathrm{o}} L_{\mathrm{c}}
\end{aligned}
$$

Knowing the heating and cooling water inlet and outlet temperatures and the mass flow rates of the heating and cooling streams, the evaporator and condenser section heat transfer rates can be calculated in accordance with the conservation of energy as:

$$
\begin{aligned}
& \dot{Q}_{\mathrm{e}}=\dot{m}_{\mathrm{e}} c_{\mathrm{p}}\left(T_{\mathrm{hi}}-T_{\mathrm{ho}}\right) \pm \dot{Q}_{\text {loss/gain }} \\
& \dot{Q}_{\mathrm{c}}=\dot{m}_{\mathrm{c}} c_{\mathrm{p}}\left(T_{\mathrm{co}}-T_{\mathrm{ci}}\right) \pm \dot{Q}_{\text {loss/gain }}
\end{aligned}
$$

The right hand terms $\dot{Q}_{\text {loss/gain }}$ in equations (2) and (3) account for the heat that is not transferred to the working fluid in the evaporator, and from the working fluid in the condenser, but that which is lost or gained from the environment through the heating/cooling jacket walls as well as through the structure supporting the thermosyphon.

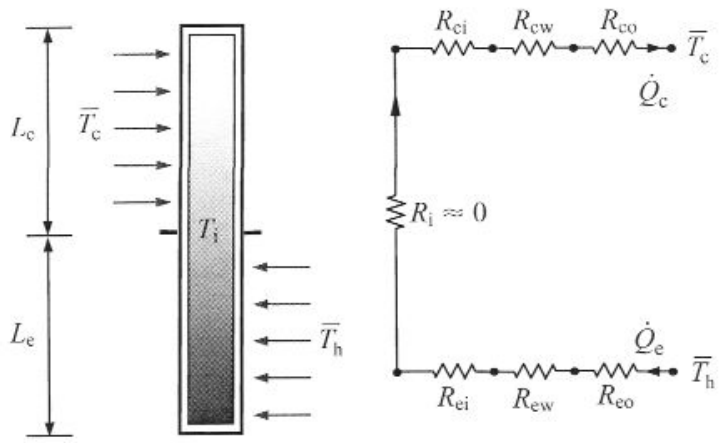

Figure 2: Thermal resistance diagram for a thermosyphon

\subsection{Thermosyphon heat transfer coefficient correlations}

The successful implementation in the design of a HPHE requires a detailed knowledge of the heat transfer characteristics. Correlations for the inside thermosyphon evaporator and condenser heat transfer coefficients and the maximum heat transfer rates are given by equations 4, 5 and 6 (Meyer and Dobson, 2005). These correlations were experimentally determined for inside pipe diameters varying from 15.0 to $32.0 \mathrm{~mm}$ and lengths of 2 to $6 \mathrm{~m}$ for a $50 \%$ liquid charge to evaporator section volume fill ratio, temperatures of 15 to $80^{\circ} \mathrm{C}$ and using $\mathrm{R} 134 \mathrm{a}$ and a butane mixture commercially sold as gas lighter fuel (50\% n-butane, $25 \%$ iso-butane and $25 \%$ propane by mass) as working fluid.

Other heat exchanger parameters such as tube and fin spacing and outside heat transfer coefficients and pressure drops are readily available in the general heat transfer and heat exchanger literature (Mills, 1995 \& Incropera and DeWitt, 2002) and hence are not given here. The maximum heat transfer rate increases significantly of about $40 \%$ (Meyer and Dobson, 2005) if a thermosyphon is inclined from the vertical. Although increasing significantly once inclined, the increase is relatively insensitive for inclination angles of 15 to $60^{\circ}$ from the vertical. For this reason, correlations were generated only for the vertical and a $45^{\circ}$ inclined orientation.

$$
\begin{aligned}
& \phi=90^{-} h_{\mathrm{ci}}=3.4516 \times 10^{5} \mathrm{fl}^{-0.455} \mathrm{Ku}^{1 . .344} \\
& \phi=45^{\circ} h_{t: \mathrm{i}}=1.4796 \times 10^{5} / a^{0.001355} \mathrm{Krt}^{1.300} \\
& \phi=90^{\circ} h_{i j}=4.61561 x 10^{\circ} \operatorname{Re}_{1}^{0.364} \\
& \left.\left[k_{1} /\left[\frac{v_{1}^{2}\left(\frac{\rho_{1}}{g}\right)}{a_{1}-\rho_{2}}\right)\right]^{1 / 2}\right]^{-2.05} \\
& \phi=45^{\circ} h_{\mathrm{ci}}=3.7233 \times 10^{-5} \mathrm{Rc}_{1}^{0.136} \text {. } \\
& {\left[k_{1} /\left[\frac{v_{1}^{2}}{g}\left(\frac{\rho_{1}}{\rho_{1}-\rho_{r}}\right)\right]^{1 / 3}\right]^{1.916}}
\end{aligned}
$$

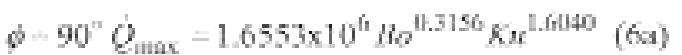

$$
\begin{aligned}
& \phi=45^{\circ} \dot{Q}_{\max }=7.4685 \times 10^{6} \mathrm{Bo}^{0.2101} \mathrm{Ku}{ }^{1.9189}(6 \mathrm{~b})
\end{aligned}
$$

\subsection{Heat exchanger thermal performance prediction procedure}

Given or assuming the physical definition of the HPHE (for example, the dimensions given in Table $2)$, the heat transfer coefficients and thermal conductivities ( $\left.h_{\mathrm{eo}}, k_{\mathrm{e}}, h_{\mathrm{ei}}, h_{\mathrm{ci}}, k_{\mathrm{c}}, h_{\mathrm{co}}\right)$, and the temperatures $\left(T_{\mathrm{hi}}, T_{\mathrm{ho}}, T_{\mathrm{ci}}\right.$ and $\left.T_{\mathrm{co}}\right)$, the internal temperature $\mathrm{Ti}$ can then be found by trial and error by guessing values for $\mathrm{Ti}$ in equation 1 such that ***. In a similar way, temperature and heat flux dependent variables may be taken into account as well.

The basic solution procedure requires the hot and cold stream inlet temperatures be specified. Starting from the 1st row (of the counter flow heat exchanger configuration shown in Figure 3, for example) cold stream outlet temperatures are estimated and then by 'marching' from one row to the next, the inlet cold stream temperature is calculated. This iteration procedure is repeated for different values of cold stream outlet until the calculated cold steam inlet temperature corresponds to the initially 


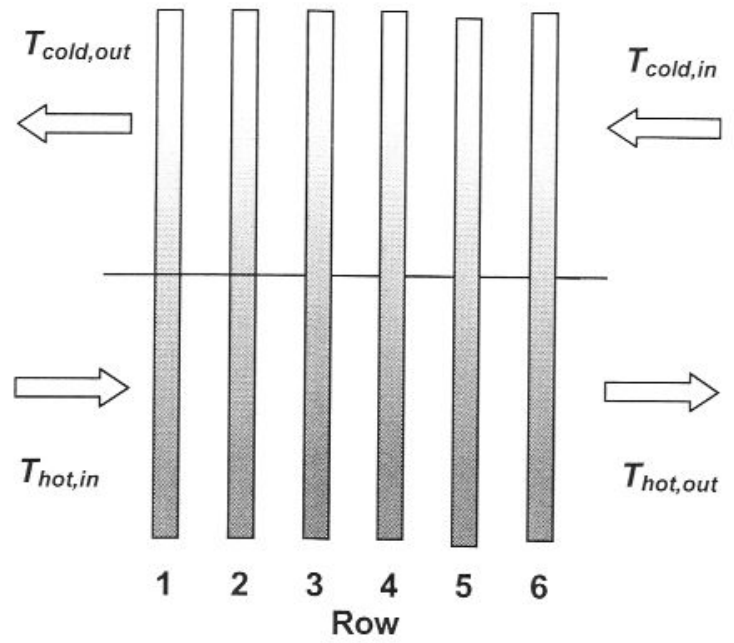

specified value.

Figure 3: Basic design configuration of the HPHE

\subsection{Computer program}

The thermal design specifications need to be specified for the HPHE and include the atmospheric pressure, hot stream inlet temperature, cold stream inlet temperature, a desired cold stream outlet temperature and the hot and cold stream mass flow rates to be specified (Table 1 ).

Table 1: Drier user's required specification for the HPHE

\begin{tabular}{ll}
\hline Inlet hot temperature & $40-60^{\circ} \mathrm{C}$ \\
\hline Inlet cold temperature & Ambient air \\
\hline Desired outlet temperature & Whatever is attainable \\
\hline $\begin{array}{l}\text { Mass flow of the air into } \\
\text { the condenser section }\end{array}$ & $0.72 \mathrm{~kg} / \mathrm{s}$ \\
\hline $\begin{array}{l}\text { Mass flow of the air into } \\
\text { the evaporator section }\end{array}$ & $0.72 \mathrm{~kg} / \mathrm{s}$ \\
\hline
\end{tabular}

\begin{tabular}{|c|c|}
\hline Working fluid & R134a \\
\hline Tube bank configuration & Al-Plate and $\mathrm{Cu}$-tube \\
\hline Evaporator length & $0.35 \mathrm{~m}$ \\
\hline Condenser length & $0.35 \mathrm{~m}$ \\
\hline Number of tube rows & 6 \\
\hline Number of tubes per row & 11 \\
\hline Longitudinal pitch & $0.0381 \mathrm{~m}$ \\
\hline Transverse pitch & $0.0381 \mathrm{~m}$ \\
\hline Fin pitch & 10 Fins/inch \\
\hline Fin thickness & $0.0002 \mathrm{~m}$ \\
\hline Outside diameter of tubes & $0.01588 \mathrm{~m}$ \\
\hline
\end{tabular}

Inside diameter of tubes

$0.01490 \mathrm{~m}$

The next step requires assumed heat exchanger geometry, including the pipe diameter length and evaporator to condenser length ratio, the number of rows and the number of tubes per row, and whether staggered or not, or whether finned or not (Table 2).

The solution now requires a series of nested trial and error iterations such that the evaporator heat transfer rate equals the condenser heat transfer rate, and whether the desired cold steam outlet condition has been met (for the assumed counter flow arrangement as assumed as shown in Figure 3). A flow diagram showing how the computer program (which was written in visual basic) is shown in Figure 4 (Meyer, 2005) and a converged solution is given in Table 3.

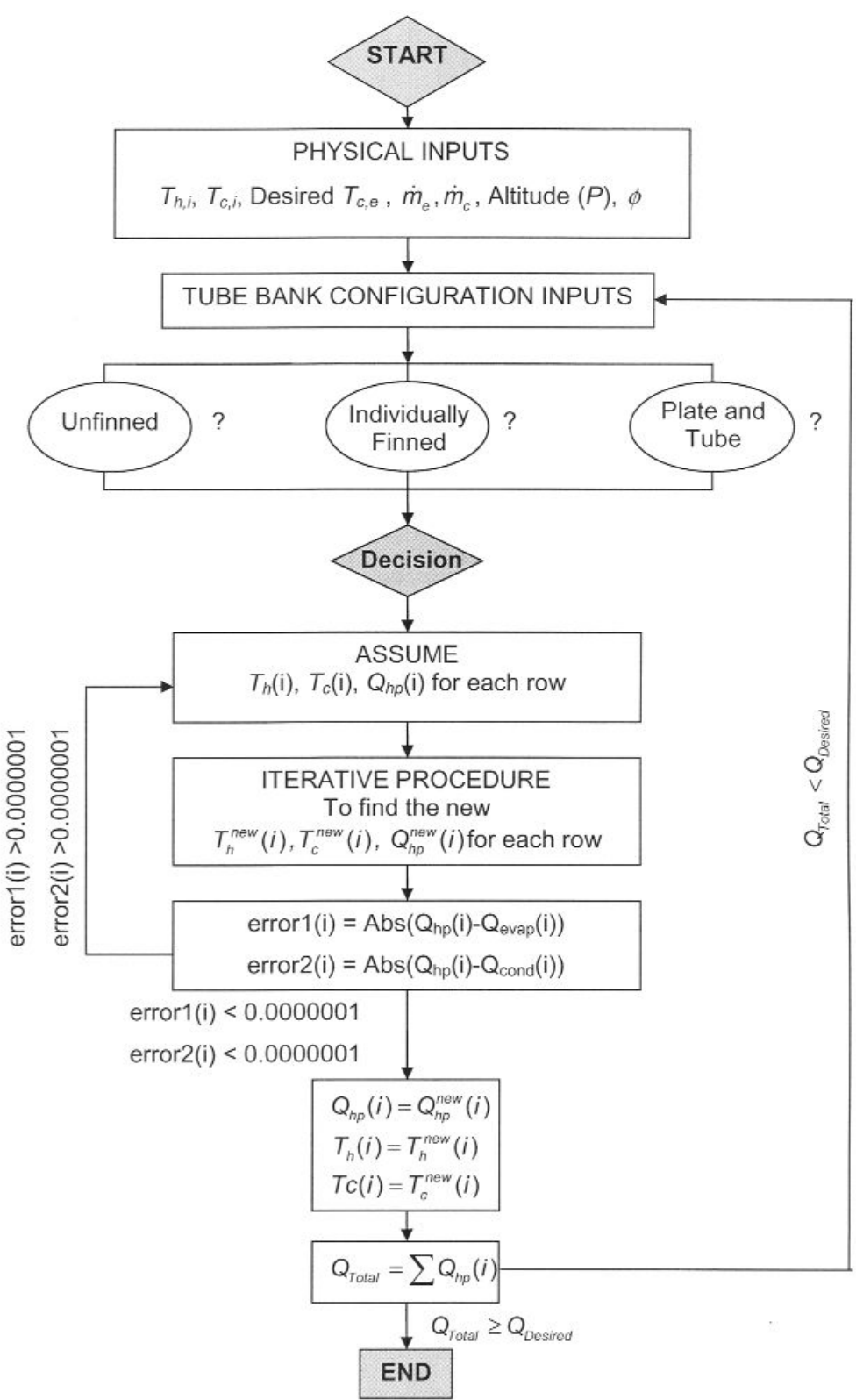

Figure 4: Flow diagram for the main iteration loop of the computer program 
Table 3: Theoretically calculated temperatures, heat transfer rate and pressure drop for the HPHE defined in Table 2 (Row $i-j$ refers to the temperature between the rows $i$ and $j$ )

\begin{tabular}{lccccccc}
\hline & Inlet, Outlet & Row 1-2 & Row 2-3 & Row 3-4 & Row 4-5 & Row 5-6 & Outlet, Inlet \\
\hline Hot stream temperature $\left[{ }^{\circ} \mathrm{C}\right]$ & 50.00 & 47.87 & 45.73 & 43.6 & 41.46 & 39.32 & 37.19 \\
\hline Cold stream temperature $\left[{ }^{\circ} \mathrm{C}\right]$ & 34.82 & 32.69 & 30.55 & 28.41 & 26.28 & 24.14 & 22.00 \\
\hline Total Pressure Drop $[\mathrm{Pa}]$ & & \multicolumn{7}{c}{ 281.53 } \\
\hline Total heat load $[\mathrm{W}]$ & \multicolumn{7}{c}{9297.95} \\
\hline
\end{tabular}

\section{Experimental set-up}

The experimental set-up consisted of the HPHE retrofitted to a standard drier using flexible ducting as shown in Figures 5 and 6. For the drier, its overall dimensions are $2.8 \mathrm{~m}$ long, $1.4 \mathrm{~m}$ wide and 1.9 $\mathrm{m}$ high. The overall dimensions of the HPHE are shown in Figure 7, its detailed specifications are given in Table 2, and it was manufactured in accordance with standards and technology for copper pipe and aluminium plate finned heat exchangers as normally applied in the HVAC industry.

The air-drier typically evaporates water from the product being dried and exhausts this moist warm air into the atmosphere. With the HPHE installed,

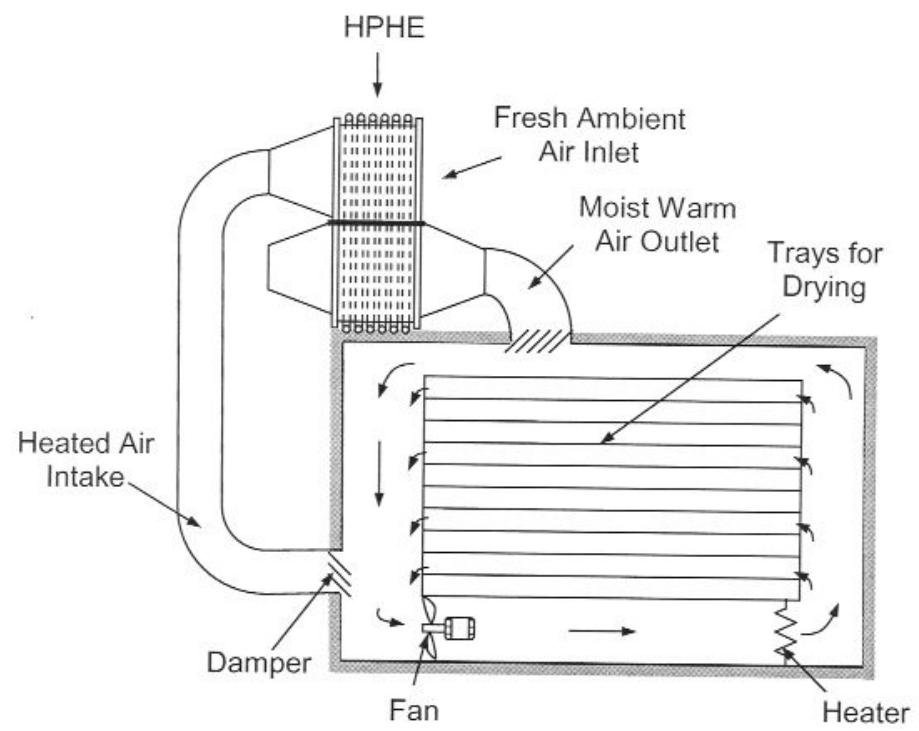

Figure 5: Schematic diagram of the HPHE retrofitted to the mini-drier

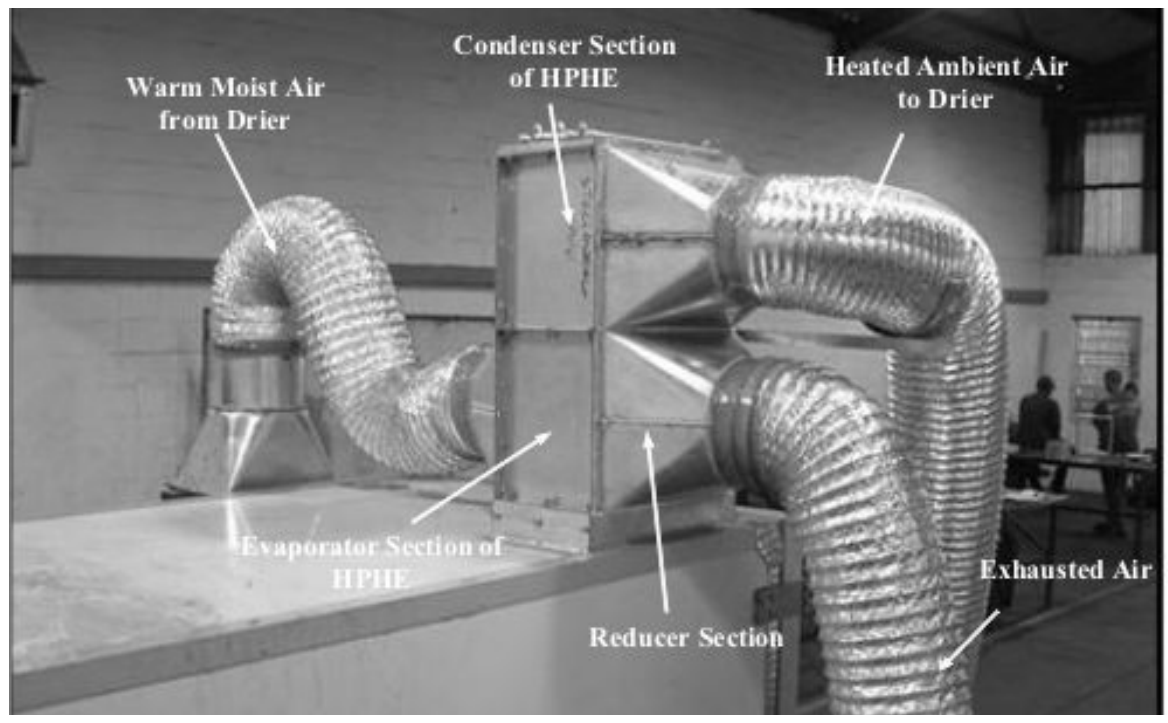

Figure 6: Image of the HPHE retrofitted to the mini-drier 


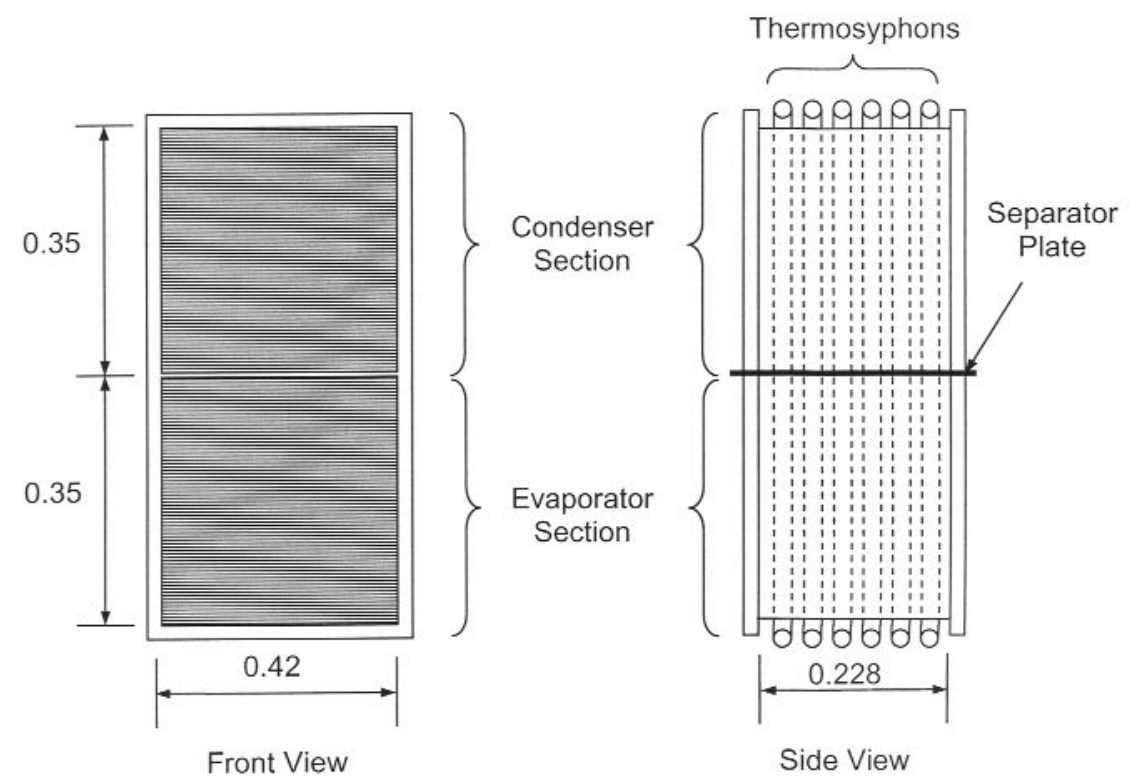

Figure 7: The as-designed and manufactured HPHE (also, see Table 2)

this warm moist air is then fed through the evaporator section of the HPHE. Fresh ambient air is then drawn through the condenser section of the HPHE, where it is heated up and is then fed back into the system thereby reducing the load on the heating elements inside the drier.

Temperature measurements were taken at the inlets and outlet of the respective hot and cold streams, and an anemometer was used to measure the flow velocities, from which the air mass flow rates could be calculated. A kWh-meter was used to measure the electrical energy consumption. To ensure accuracy and repeatable drying operations, the product to be dried was simulated using wet towels laid out on the drying racks. Tests runs with and without the HPHE could thus be compared.

\section{Results and discussion}

\subsection{Drier-HPHE experimental results}

The temperature and heat transfer rates for the first 45 minutes of operation of the drier (with the HPHE fitted) are given in Figure 8. After 35 min- utes, the drier thermostat (set at a temperature of $50^{\circ} \mathrm{C}$ ) starts to control the drier temperature and the heat transfer rate between the hot and cold streams varies between 7700 and $9000 \mathrm{~W}$.

The drying period was continued for a total of 5 hours and the kWh-meter electrical power consumption readings at different times are given in Figure 9. With the HPHE installed, the total drier power consumption is $35.4 \mathrm{kWh}$ and, for identical operation of the drier, but without the HPHE, the power consumption is $52.2 \mathrm{kWh}$.

\subsection{Experimental verification of the theoretical HPHE design}

The experimental heat transfer rates at different hot and cold stream temperature (as reflected in Figure 8 ) are compared with the theoretical predicted values in Figure 10. For temperature differences above $15^{\circ} \mathrm{C}$, the mathematical model results compare reasonably well with the experimental values.

At the lower temperature differences, the correspondence becomes less favorable and erratic. This

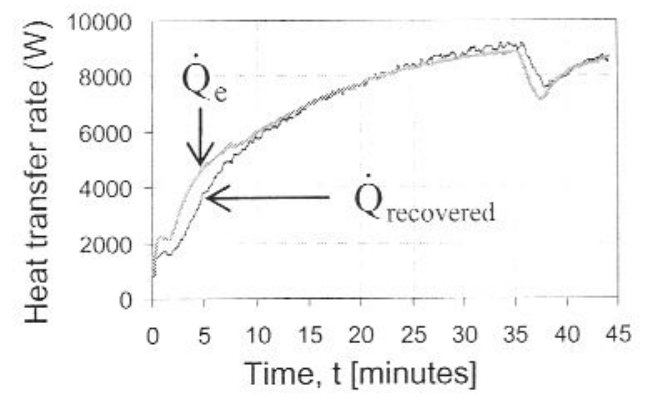

Figure 8: Experimental temperature and heat transfer rate as a function of time for the HPHE for $\dot{m}_{\mathrm{c}}=0.562 \mathrm{~kg} / \mathrm{s}$ and $\dot{\mathrm{m}}_{\mathrm{h}}=0.571 \mathrm{~kg} / \mathrm{s}$ 


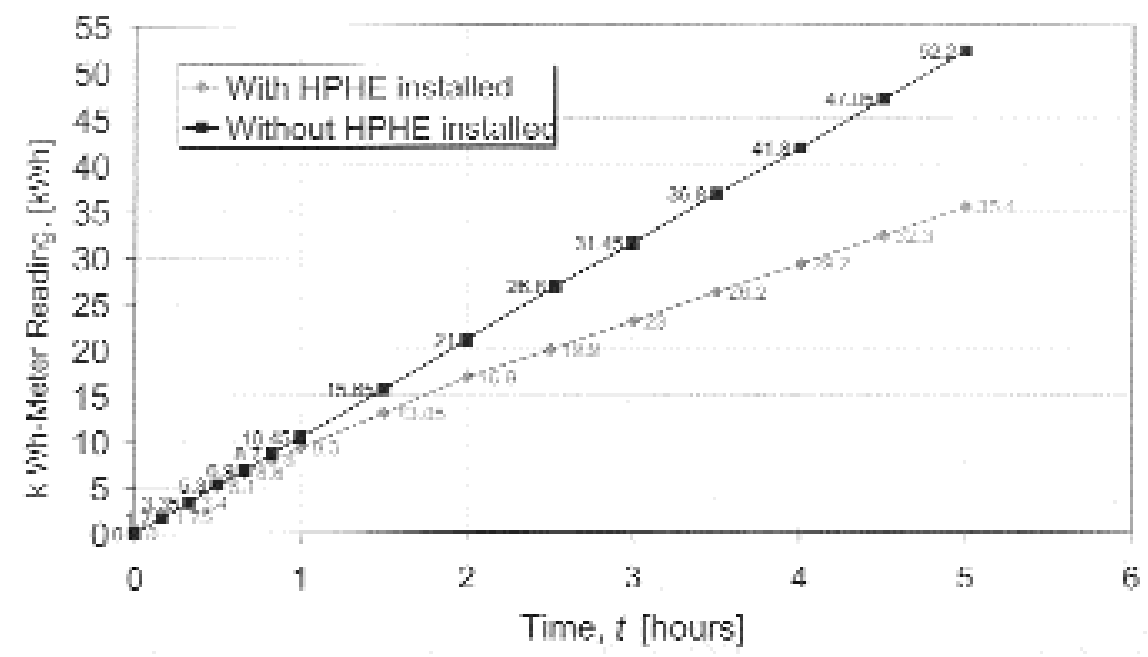

Figure 9: Energy consumption (kWh-meter readings) for the drier unit operation with and without the HPHE

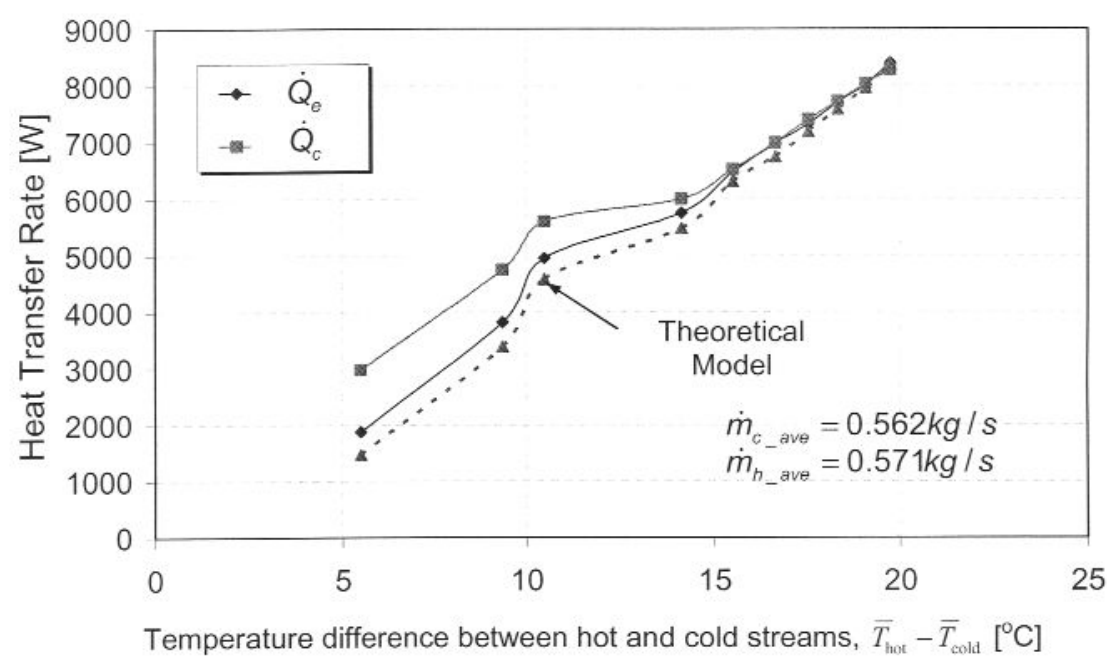

Figure 10: Theoretically predicted and experimentally determined HPHE heat transfer rates as a function of different average temperature differences between the hot and cold streams

is to be expected because at the lower temperature differences errors in temperature measurements become more significant. The smaller the temperature differences, the greater the heat exchange area needed to transfer the same amount of heat.

A larger heat exchange area implies a more expensive heat exchanger and, hence, to keeps costs down it is preferred to operate heat exchangers at temperature differences greater than $15^{\circ} \mathrm{C}$. The reason for the 'kink' at a temperature difference of $11^{\circ} \mathrm{C}$ is attributed to a discontinuity at the range crossover point from one heat transfer coefficient correlation to another used in the theoretical model.

\subsection{Economic evaluation}

The results of an economic evaluation of the energy saving using the HPHE are given in Table 4. The actual material and labour (costs including a nominal mark-up) incurred to retrofit the HPHE are reflected in Table 4, which amounted to R7 469, and with the energy saving minus additional running costs of R2 321 yielded a simple payback period of 3.2 years. The anti-corrosion epoxy protective coating of R2231 constituted a significant additional cost.

The manufacturer of the HPHE claimed that their experience showed that it would not be necessary for typical agricultural produce drying. The manufacturer of the drier, on the other hand, insisted that the protective coating was necessary. Had this cost, however, been incurred, the payback period would have been 2.3 years. Had the HPHE been included in the design as a standard production feature, an even lower payback period of about 1.8 years is deemed possible?

\section{Conclusions}

The heat transfer rate between the hot and cold 
Table 4: Economic evaluation (in 2004-Rands)

\begin{tabular}{|c|c|c|}
\hline & Additional costs with HPHE: & \\
\hline & Standard HPHE & R2660 \\
\hline & Anti-corrosion epoxy coating & $\mathrm{R} 2231$ \\
\hline & Variable speed fan & $\mathrm{R} 1000$ \\
\hline & Ducting & $\mathrm{R} 78$ \\
\hline & Reducer sections & R 500 \\
\hline & Labour & $\mathrm{R} 1000$ \\
\hline 1 & Total HPHE installation cost & R7469 \\
\hline \multirow[t]{6}{*}{2} & Additional HPHE running cost & R400/year \\
\hline & Energy consumption without HPHE: & \\
\hline & Electrical energy consumption & $10.44 \mathrm{kWh} / \mathrm{h}$ \\
\hline & No. of operating shifts per annum & 250 \\
\hline & Number of hours per shift & 18 \\
\hline & Cost of electricity & R0.18/kWh \\
\hline \multirow[t]{6}{*}{3} & Annual cost of energy without HPHE & $\mathrm{R} 8456$ \\
\hline & Energy consumption with HPHE: & \\
\hline & Electrical energy consumption & $7.08 \mathrm{~kW} / \mathrm{h}$ \\
\hline & No of operating shifts per annum & 250 \\
\hline & Number of hours per shift & 18 \\
\hline & Cost of electricity & $\mathrm{R} 0.18 / \mathrm{kWh}$ \\
\hline 4 & Annual cost of energy with HPHE & R5735 \\
\hline 5 & Saving per year $(3-4-2)$ & R2321 \\
\hline 6 & Simple payback period $(1 / 5)$ & 3.2 years \\
\hline
\end{tabular}

streams of the heat pipe (thermosyphon) heat recovery heat exchanger is accurately predicted by the theoretical model for average temperature difference between the two streams of greater than $15^{\circ} \mathrm{C}$.

The experimental evaluation of the heat recovery heat exchanger retrofitted to the mini-drier yielded a $32 \%$ saving of R2 321 per annum (item 5, Table 4) and for the total heat pipe installation cost of R7 469 (item 1, Table 4) a simple payback period of 7469/2321 = 3.2 years was obtained. A significantly lower payback period is deemed possible if the heat exchanger be included in the design of the mini-drier as a standard production feature.

\section{References}

Dunn DP and Reay D, 1994, Heat pipes, $4^{\text {th }}$ Edition, Pergamon.

Incropera FP and DeWitt DP, 2002, Fundamentals of Heat and Mass Transfer, Wiley.

Meyer A, 2004, Development of a Range of Air-to-Air Heat Pipe Heat Recovery Heat

Exchangers, MSc Thesis, University of Stellenbosch, Stellenbosch.

Meyer A and Dobson RT, 2005, Thermal performance characterization of R134a and Butane charged twophase closed thermosyphons, $R \& D$ Journal (submitted for review and publication).

Mills AF, 1995, Heat and Mass Transfer, Richard D. Irwin.

Pioro LS and Pioro IL, 1997, Industrial Two-phase Thermosyphons, Begell House.

Russwurm AE, January 1980, Q-pipes add a new dimension to waste heat recovery, recycling energy - Part 1 , Heating, Air Conditioning \& Refrigeration (Now Refrigeration and Air Conditioning), pp 27-39.

Russwurm AE, March 1980, Recovering waste heat with Q-pipes, recycling energy - Part 2 - Recycling energy, Heating, Air Conditioning \& Refrigeration (Now Refrigeration and Air Conditioning), pp 45-49.

Received 20 June 2005; revised 30 August 2005 